\title{
Distribution of Tursiops truncatus in Southeastern Brazil: a Modeling Approach for Summer Sampling
}

\author{
Rodrigo H. Tardin ${ }^{1,2 *}$, Sheila M. Simão ${ }^{2}$ \& Maria Alice S. Alves ${ }^{3}$
}

\author{
${ }^{1}$ Programa de Pós-graduação em Ecologia e Evolução, Universidade do Estado do Rio de Janeiro - UERJ, \\ Rio de Janeiro, RJ, Brazil \\ ${ }^{2}$ Laboratório de Bioacústica e Ecologia de Cetáceos, Departamento de Ciências Ambientais, \\ Universidade Federal Rural do Rio de Janeiro - UFRRJ, Seropédica, RJ, Brazil \\ ${ }^{3}$ Departamento de Ecologia, Universidade do Estado do Rio de Janeiro - UERJ, Rio de Janeiro, RJ, Brazil
}

\begin{abstract}
Distribution modeling is a relatively new tool to study cetaceans distribution and is used to understand their relationships with the habitat, which in turn, can be used for several purposes. This is the first attempt to model Tursiops truncatus distribution in South- Atlantic Ocean. A Generalized Additive Model (GAM) was developed to investigate how the distribution of $T$. truncatus in Cabo Frio, Brazil, during summer (December to February) is influenced by depth, distance to coast, slope,. Furthermore, we tested the efficiency of a model with number of groups (total occurrence) as response variable compared to a presence-absence data. Our results indicated that total occurrence model was more robust than presence-absence. Dolphins were found regarding to depth most frequently around 30-60 m and decreasing in more profound depths. Dolphins occurrence decreased as distance to coast increased. Our results show that Cabo Frio is an important site for T. truncatus since it may provides feeding resources and a safe place against predators. However the fast development of human activities may threaten this important area and therefore this dolphin species in Brazilian waters.
\end{abstract}

Key words: Bottlenose Dolphin, Cabo Frio, Arraial do Cabo, Habitat Modelling, Distribution Modelling

\section{Introduction}

Distribution studies of highly mobile marine species pose challenges for researchers for many years. Marine ecosystems are fluid and dynamic, in which large spatial and temporal differences may be observed in scales from meters to kilometers and on diel to decadal scales (Redfern et al. 2006). For large animals, such as cetaceans, the difficulties to study how they distribute are large. This is true because their extended life span, slow reproduction and high capacity of movement (Acevedo-Gutierrez 2008).

Distribution modeling is a relatively new tool to study distribution of cetaceans and intrinsic factors of this taxon (e.g. migratory behavior and social organization) hamper the fast development and application of the models (Redfern et al. 2006). In general, distribution modeling is used to determine their distribution within a given habitat and allow its use in a conservation biogeography framework (Corkeron et al.

*Send correspondence to: Rodrigo Tardin

Programa de Pós-graduação em Ecologia e Evolução, Universidade do Estado do Rio de Janeiro - UERJ,

Av. São Francisco Xavier 524, PHLC, 2 andar, sala 224,

Maracanã, CEP 20550-013, Rio de Janeiro, RJ, Brazil

E-mail:rhtardin@gmail.com
2011). For species inhabiting coastal ecosystems, such as Tusiops truncatus (bottlenose dolphin) these studies are specially need, due tothe many anthropogenic threats that they are subjected. Some of these threats are: high boat traffic, which can alter dolphins behavior (Lusseau 2003), fisheries interaction resulting in injuries (Nery et al. 2008) and diseases resulting from human activities, such as lobomycosis-like disease (Van Bressem et al. 2009). Since the conservation of a species depends on the understanding of the relationship between populations and their habitat (Cañadas et al. 2005), modeling T. truncatus distribution may help to understand which habitats are used with higher frequency and what environmental features (biotic and/or abiotic) will improve their conservation.

Tursiops truncatus have a wide distribution range, occurring in tropical, sub-tropical and temperate habitats $\left(45^{\circ} \mathrm{N}-45^{\circ} \mathrm{S}\right.$; Wells \& Scott 2008). In Brazilian waters, T. truncatus distribution is continuous from Amapá to Rio Grande do Sul states (IBAMA 2001), also occurring in some islands [Fernando de Noronha (Silva Jr. \& Silva 2004), São Pedro e São Paulo (Caon \& Ott 2004), Atol das Rocas (Baracho et al. 2008) and Cagarras (Lodi \& Monteiro-Neto 2012)]. 
Tursiops truncatus is one of the best known species of delphinids around the world, in which some populations have been continuously monitored in long-term [e.g. Shark Bay (Connor et al. 2000) and Sarasota Bay (Wells 1991)]. Despite being well studied in the world, just a few studies on ecological and behavioral aspects of this species were conducted in Brazilian waters. Distribution aspects in Brazilian waters are known for some areas [e.g. Trindade Island (Carvalho \& Rossi-Santos 2011), Rio de Janeiro state (Lodi et al., 2008)], but, until the present there is no published study that models T. truncatus distribution with environmental variables to the Southwestern Atlantic Ocean.

\section{Since the National Action Plan of Small Cetaceans} proposed by the Instituto Chico Mendes de Conservação da Biodiversidade, a governmental institute for conservation of biodiversity, reports that an important goal to T. truncatus conservation is to better investigate their distribution patterns in Brazilian waters (Barreto 2011), our objectives were to: a) formulate, develop and validate a distribution model to understand how some environmental variables influence distribution of this species in Cabo Frio, Rio de Janeiro state (RJ); b) test the efficiency of models using different response variables.

\section{Methods}

The Cabo Frio coast $\left(22^{\circ} 50^{\prime} 21^{\prime \prime} \mathrm{S} ; 41^{\circ} 54^{\prime} 37^{\prime \prime} \mathrm{W}-23^{\circ} 00^{\prime}\right.$ $18^{\prime \prime} \mathrm{S} ; 42^{\circ} 05^{\prime} 53^{\prime \prime} \mathrm{W}$ ) is marked by a change in the shoreline from a north-south to a south-west to north-east orientation, and has a steep slope (Figure 1) (De Leo \& Pires-Vanin 2006). Throughout the year, there is a mixture of two water masses (the Brazil Current and the South Atlantic Central Water), which is strongly influenced by the north-northeast wind regime, which produces an upwelling phenomenon that is especially prevalent during spring and summer (Carbonel 1998). The upwelling results in high primary productivity and high fish yields, favoring the occurrence of different cetacean species (Keiper et al. 2005), compared to non-upwelling habitats. These conditions allow these habitats to be important for these species, especially because cetaceans need high energetic requirements (Costa 2008).

We conducted four monthly boat trips (mean duration $5.8 \mathrm{~h}$, minimum $=3.25 \mathrm{~h}$, aximum $=8.00 \mathrm{~h}$ ) during the summer (December, January and February) of 2011/2012 (10 boat trips in 2011 and 12 boat trips in 2012) using a $6.5 \mathrm{~m}$ inflatable boat equipped with a 150-hp engine. Random routes were chosen to maximize coverage of the study area (Figure 1) and when we spotted a group of dolphins we slowed boat's velocity. From 500 to 500 m we collected GPS location using a GPS GARMIN VISTA CX and number of groups was used as our response variable, since the group size varied greatly from 4 to 120 individuals ( $R$. Tardin unpublished data). Visual counting was the method used to measure group size. We plotted the number of groups on the nautical chart (number 15051, Diretoria de Hidrografia e Navegação) using the software ArcGis ${ }^{\circledast}$. Our definition of group followed the $10 \mathrm{~m}$ chain rule proposed by Smolker et al. (1992), in which individuals $10 \mathrm{~m}$ apart from each other were considered as belonging to the same group.

For the purposes of our analysis, the studied area was divided in 99 grids of $2 \times 2 \mathrm{~km}^{2}$, where for each grid we accounted the number of groups and values of different environmental variables. We built two models using the same explanatory variables but with different response variables. Our response variable was treated in the first model as encounter rate (ER) and in the second model as presence-absence only. Encounter rate was calculated as just the number of sighted groups in each grid/number of days each grid was sampled.

We used the encounter rate in the first model because it assesses the frequency of usage of an area according to the first location of the dolphin group for each sighting (Blasi \& Boitani 2012). Number of sighted groups was corrected by the number of days each grid was sampled, because our studied area was heterogeneously sampled. Therefore, if in a given grid we accounted four different groups and we sampled this grid eight different days, until the end of data collection, the final occurrence data was: $4 / 8=0.5$ and not four as if it would be if effort was not corrected for each occurrence. Number of sighted groups was used, as done in Forney (2001), Bräger et al. (2003), Garaffo et al. (2011) and Blasi \& Boitani (2012), instead of group size because groups varied greatly in respect of number of individuals.

In the second model, if a group was seen at a given grid we accounted only the presence (i.e. one occurrence) regardless how many different days it was observed at the area. The sampling design was corrected by adding an offset with the total number of times each grid was visited in the model.

The environmental variables that we chose as explanatory variables were: mean depth, distance to coast and slope. Mean depth was obtained or derived from the nautical chart, in which the three closest values of depth inside a particular grid from the GPS location were used to provide a mean number. Distance to coast was also measured from the nautical chart and was defined as the closest portion of land from the GPS position, including coastal reefs, islands, shoreline, etc. Slope was calculated following Garaffo et al. (2007): $\left(\mathrm{D}_{\max }-\mathrm{D}_{\min }\right) / \mathrm{DI}$, where $\mathrm{D}_{\max }$ is maximum depth in the grid, $\mathrm{D}_{\min }$ is the minimum depth in the grid and DI is the distance $(\mathrm{m})$ between the points of maximum and minimum depth, expressed in units of meters per kilometer. The potential distribution map was generated using Krigging technique included in ArcGis 9.2.

To investigate T. truncatus distribution we used a Generalized Additive Model (GAM) that is a semi-parametric form of the Generalized Linear Model (GLM). In GAM the only assumptions made is that components are smooth and functions are additive (Hastie \& Tibshirani 1990). In this generalized model, there is a link function used to establish a relationship between the mean of the response variable and the smooth function of the explanatory 


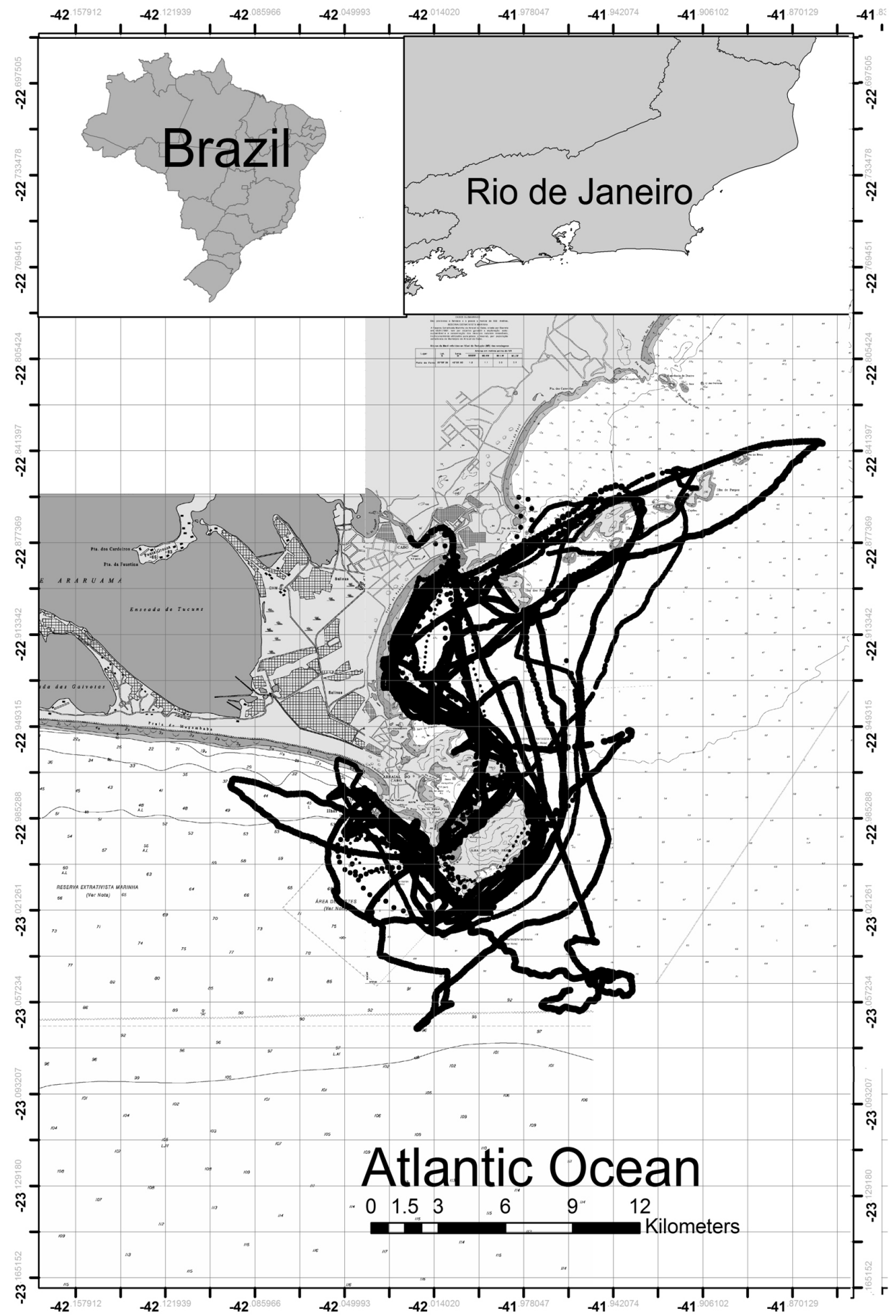

Figure 1. Study area, located at Cabo Frio coast, Rio de Janeiro, Southeastern Brazil. Lines indicate survey routes along the studied area during summer 2011 and 2012.

variable. The advantage in using GAMs is the ability to work with non-linear and non-monotonic relationships between the response variable and the set of explanatory variables (Guisan et al. 2002). Furthermore, in GAMs the association between response and explanatory variables derives from data itself and not from the model, because it does not assume any kind of parametric assumption (Yee
\& Mitchel 1991). Therefore, this model can help to develop more robust ecological relationships (Guisan et al. 2002). Therefore, we developed a GAM model using R software (R Core Developmental Team, 2012) with mgcv package (Wood 2011).

Our habitat model that used total occurrence assumed a Gamma distribution error structure, with a link log 
function. The presence-absence model assumed a binomial distribution error structure with a link logit function. For both models, to avoid overfitting of data, which can make biological data hard to interpret, the degrees of freedom were constrained to 4 (Marubini et al. 2009) and the Gamma argument set to 1.4 (Kim \& Gu 2004). Therefore, we tested two different models with two different response variables:

- A model using as response variable total occurrence;

- A model using presence-absence of groups as response variable.

Thin Plate Regression Splines were used to adjust the penalized parameters. This method has the advantage of not put explicitly the knots or select the function basis (Wood 2006). Since model selection still is subject to debate, we used two different methods of model selection: Generalized Cross Validation scores (GCV) and Akaike's Criterion Information (AIC). Cross Validation is a technique that iteratively withheld subsets of original data to provide the best fit models (Redfern et al. 2006). The 'mgcv' package uses an automated generalized cross-validation for model fitting (GCV score), which has the advantage to effectively choose the degree of freedom when parameter scale is unknown (Wood 2006). This method was used in some cetacean distribution modeling (e.g. Gilles et al. 2011, Anderwald et al. 2012, Dalla-Rosa et al. 2012). The lowest the GCV score the best fit a model has. The AIC is a method that calculate the explanatory power of a variable against the decrease in the degrees of freedom while decreasing the number of variables included in the model, which reduces the bias in the model (Redfern et al. 2006). This is a largely used criterion for model selection in cetacean literature (e.g. Marubini et al. 2009, Garaffo et al. 2010, Keller et al. 2012). This criterion ranks models according the value of AIC of each model, in which the lowest value represent the most parsimonious model and therefore more plausible. Models presenting differences less than two were considered to have equivalent support (Burnham \& Anderson 2002).

Furthermore, the method used to adjust the parameters was also useful at model selection because they present features that penalize the smoothing process, which includes a shrinkage component. Thus, when parameters are very large the smoothing becomes zero. This allows an automatic selection of the parameters that removes the model term (Wood 2006).

\section{Results}

We conducted twenty-two boat trips with 125.7 hours of effort and 8.3 hours of direct observation (6.6\%). The suitability map shows the higher values near the islands far from the continent (Figure 2). A total of 36 Tursiops truncatus sightings were made and dolphins sighting rate was of 0.11 dolphins/grid, in which highest encounter rates are also around islands far from the continent (Figure 3). We observed dolphins in depths that varied from 12.7 to
$83 \mathrm{~m}$, from 0.3 to $3.8 \mathrm{~km}$ of the coast and maximum slope of 0.08 (Table 1 ).

The GAM using total occurrence as response variable explained $24.3 \%$ of the variance and variables retained in the final model were depth and distance to coast (Table 2). In this model, the relationship between depth and number of groups corrected by the effort had a peak of observations around 30-60 m with a slight decrease in deeper depths (Figure 4a) and a decrease in occurrence as distance to coast increased (Figure 4b).

The GAM using presence-absence data explained 33.9\% of the variance and distance to coast and slope were retained in the final model (Table 2). In this model, the relationship between distance to coast and number of groups corrected by the effort showed an increase in occurrence as distance to coast increased (Figure 5a) and a decrease of occurrence as slope increased (Figure 5b). Both model selection criteria selected the total occurrences model as the best and most parsimonious model (Total Occurrences Model - d.f. $=11.5$, $\mathrm{AIC}=-347.4-\mathrm{GCV}$ score $=2.76$; Presence-absence Model - d.f $=10.8$, AIC $=100.8-$ GCV score $=71.4$ ).

\section{Discussion}

Until now, this is the first study to model T. truncatus distribution in Southwestern Atlantic Ocean. The suitability and ER distribution maps showed that some highest values were found near the islands far from the continent. This occurred since these areas were less surveyed and almost always we sighted groups of dolphins. Our results indicated that the model that quantified the number of groups inside

Table 1. Summary statistics of explanatory variables where at least one group of Tursiops truncatus was observed in Cabo Frio, RJ, Brasil.

\begin{tabular}{lcccccc}
\hline Variables & N & Mean & Median & Mode & SD & CV (\%) \\
\hline $\begin{array}{l}\text { Depth } \\
\text { Distance }\end{array}$ & 27 & 40.0 & 38 & Multiple & 16.8 & 42.0 \\
to coast & 27 & 1.5 & 1.4 & 0.3 & 1.2 & 75.3 \\
Slope & 27 & 0.02 & 0.02 & 0.0009 & 0.02 & 96.1 \\
\hline
\end{tabular}

Table 2. Generalized Additive Model results for Total Occurrence and Presence-absence Model for Tursiops truncatus in Cabo Frio, RJ, Brasil. D.F = Degrees of freedom.

\begin{tabular}{lccc}
\hline \multicolumn{4}{c}{ Total Occurrence Model (F-ratio) } \\
\hline \multicolumn{1}{c}{ Variables } & D.F. & Estimate & P \\
\hline Depth & 2.1 & 5.0 & $<0.001$ \\
Distance to coast & 2.4 & 10.3 & $<0.001$ \\
Slope & 1.7 & 1.6 & 0.2 \\
Presence-absence Model (F-ratio) & & & \\
Depth & 1 & 0.3 & 0.6 \\
Distance to coast & 1 & 6.3 & $<0.001$ \\
Slope & 1.8 & 6.5 & $<0.001$ \\
\hline
\end{tabular}




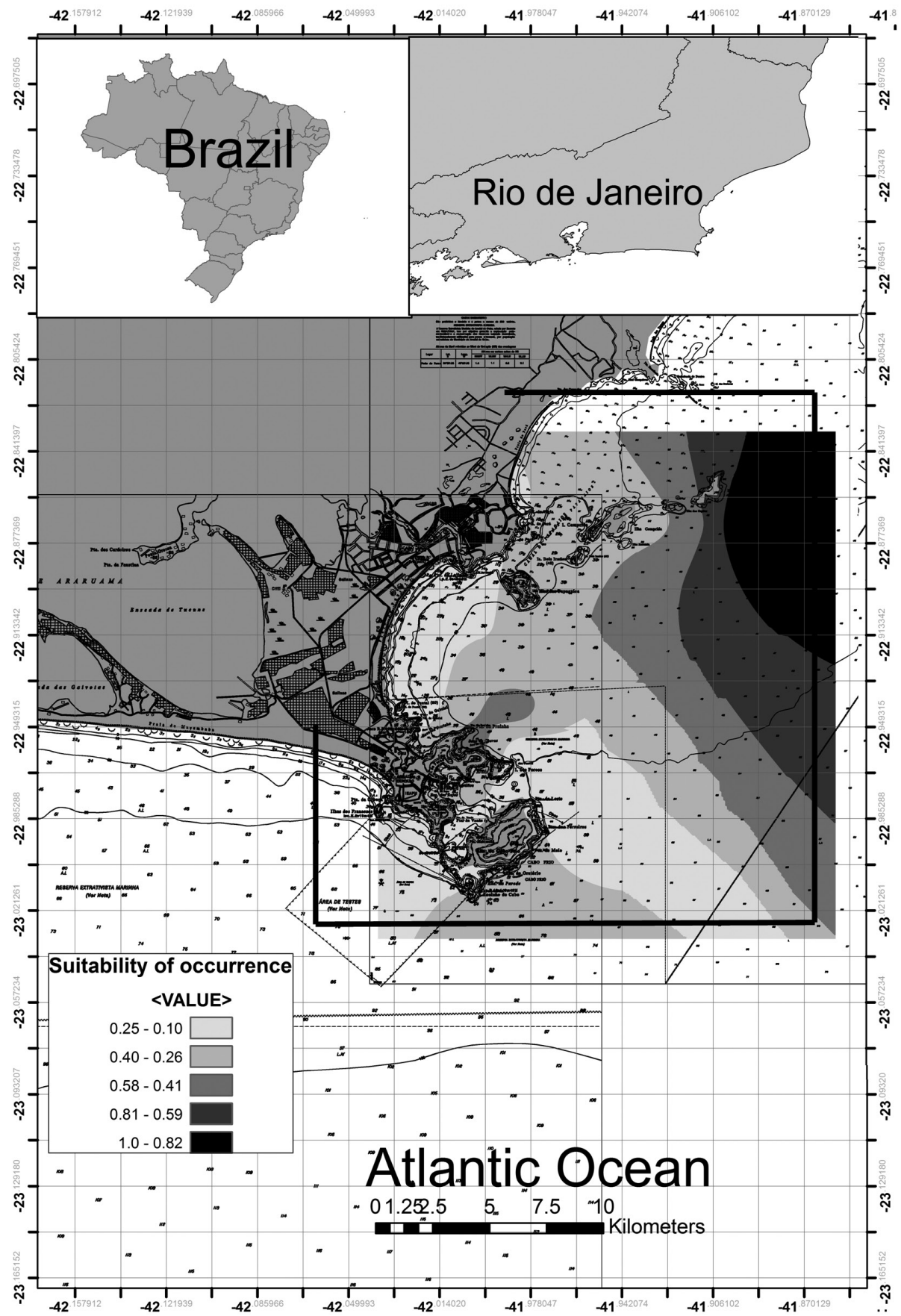

Figure 2. Suitability of occurrence given the empirical data for Tursiops truncatus located in State of Rio de Janeiro, Southeastern Brazil. Continuous black line delimitating a sub-area, inside the study area, indicates where boat trips were conducted. Grids in blank accounts for no observation.

each grid corrected by the effort presented a more robust framework to understand what environmental variables influenced T. truncatus distribution in Cabo Frio. This suggest that measuring the number of groups in quantitative way, presenting sighting rate data, may provide a more complete and solid understanding of species distribution models. Indeed, by only accounting presence-absence data, the model presents a more qualitative than quantitative data. However, in many situations this is the only way to register cetaceans distribution and yet, provide a solid database to develop a distribution model (e.g. Viddi et al. 2010). However, few studies compared model robustness regarding to different response variables as we did in the present study. In a study conducted in Golfo Nuevo, Argentina, that modeled dusky dolphin (Lagenorhynchus obscurus) distribution, the model with presence-absence data was more robust than with gamma error structure (Garaffo et al. 2010). In our case, we showed that total occurrence data produces 


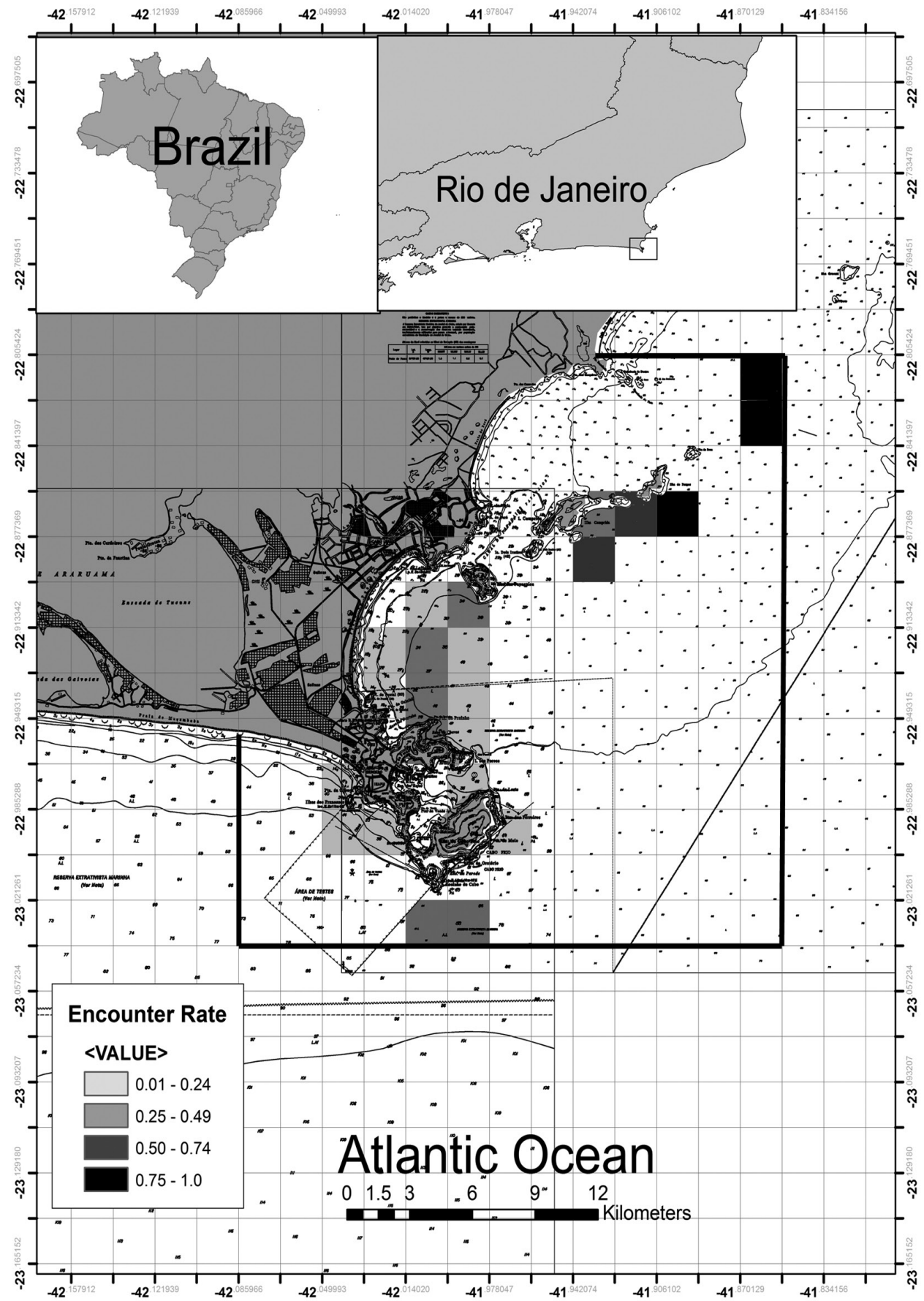

Figure 3. Study area showing encounter rates for Tursiops truncatus in each grid at Cabo Frio, Rio de Janeiro. Continuous black line delimitating a sub-area, inside the study area, indicates where boat trips were conducted. Grids in blank accounts for no observation.

better models than presence-absence data for T. truncatus and this approach must be used to better understand the distribution of this species in Cabo Frio.

In total occurrences model, depth and distance to coast were retained at the final model. Our results indicated that during summer, dolphins had a preference for waters around 30-60 meters of depth. According to Wells \& Scott (2008), T. truncatus have an opportunistic feeding habit, preying pelagic, demersal or benthic species. Therefore, the distribution observed at the area, occupying different depths, may be a reflex of its feeding behavior, in which dolphins may be using these habitats to forage in search for potential prey, the most frequent behavior observed during the period (unpublished data). In fact, cetaceans have to be constantly foraging to attend their high energetic demand (Costa 2008). The influence of depth over T. truncatus distribution is reported to other regions. In a study conducted with this species in Alborán Sea, Spain, it was reported that depth significantly influenced $T$. truncatus distribution, in 

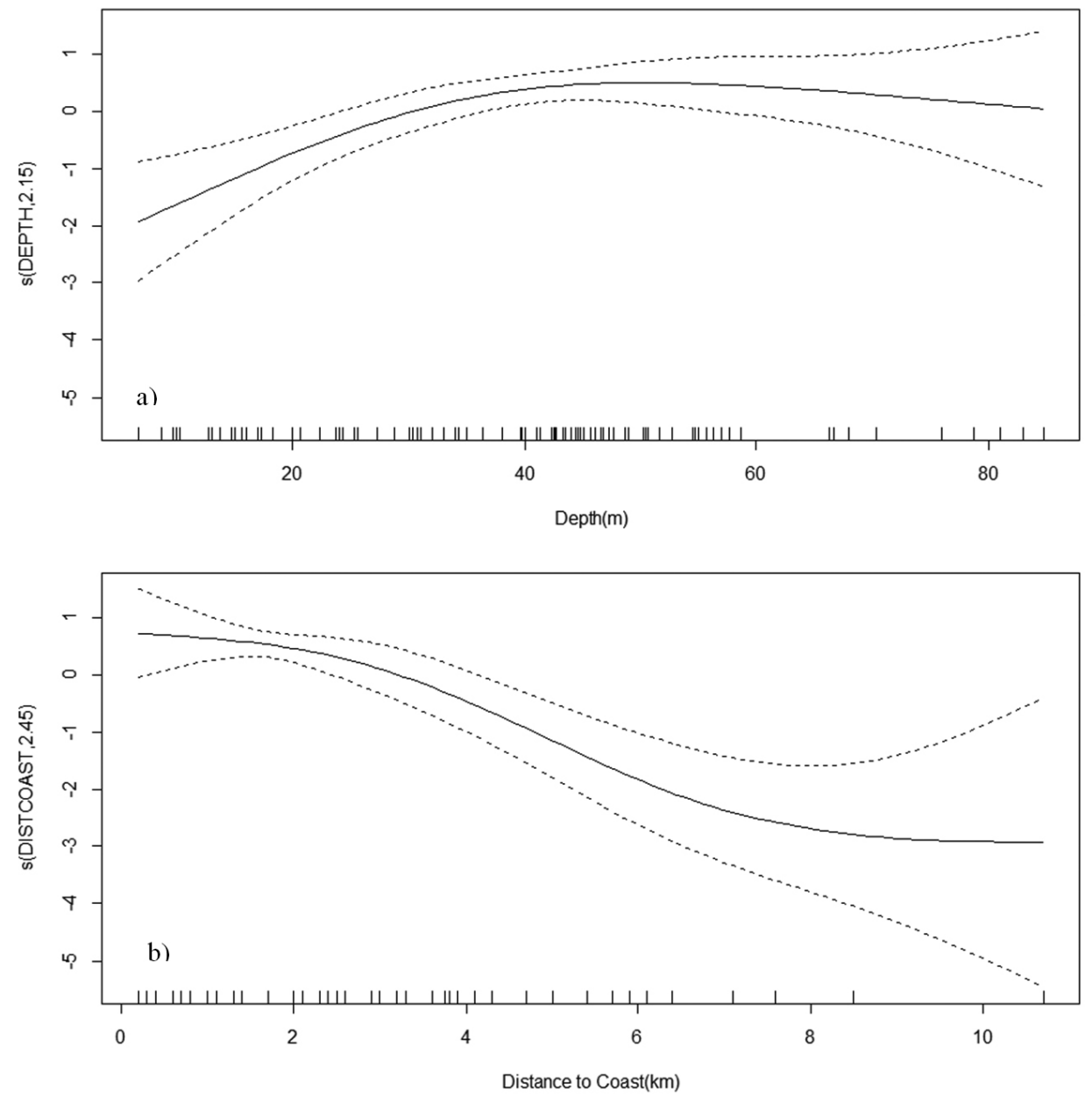

Figure 4. Generalized additive model smoothing curves for total occurrences model showing only significant parameters on Tursiops truncatus in Cabo Frio, RJ, Brazil. Y axis represents spline smooth functions and degrees of freedom are shown in parenthesis. Tickmarks in X axis indicate distribution of observations (with and without sightings). Dashed lines designate 95\% confidence interval for smoothing functions. a) Depth, b) Distance to coast,

which the highest encounter rates were around $200 \mathrm{~m}$, the shallowest of the region (Cañadas et al. 2002).

Our model indicated that dolphins' occurrence was highest near the coast and lowest far from the coast. As the variable distance to coast included the closest portion of land from coastal reefs, islands and shoreline, the highest encounter rate around the islands far from continent (Figure 3) may have driven the model to select highest occurrence near the coast than far from the coast. In other words, coast in this case is not necessarily the same as continent. Thus, the distribution closer to the coast (mainly around the islands) as we observed in our study may also be a reflex of their feeding behavior. In this situation, dolphins may be searching for food near rocky coast, since some fishes that live associated to these habitats are part of T. truncatus diet (e.g. Diplodus argenteus (Di Beneditto et al. 2001)). Similarly, in a study conducted in northeast Scotland, T. truncatus were seen in regions closest to the coast (Bailey \& Thompson 2009), as well as in a study carried out in Mediterranean Sea (Azzelino et al. 2012), corroborating our findings.
Tursiops truncatus living in close association with islands is not uncommon in the literature [e.g. Azores island, Portugal (Silva et al. 2008), Trindade island, Brazil (Carvalho \& Rossi-Santos 2011), Aeolian archipelago, around French and Italian waters (Blasi \& Boitani 2012)]. These habitats may be source of food resources and dolphins may gather around them to forage. The associated ictiofauna of the region presents fishes of tropical and sub-tropical species, in which most of them are omnivorous (Ferreira et al. 2004) and therefore, dolphins must be plastic in their behavior to take advantage from the situation.

Our results show that Cabo Frio is an important area for T. truncatus during summer. This region may provide energetic resources that are important to maintain these highly energetic predators. Moreover, Cabo Frio may be a valuable spot for these animals since it may represent a safer place than open ocean areas, in which predators such as Orcinus orca (Killer whales) and large sharks, such as Sphyrna spp. threatens their survival, especially for calves. This seems to be true because Cabo Frio has a steep slope 

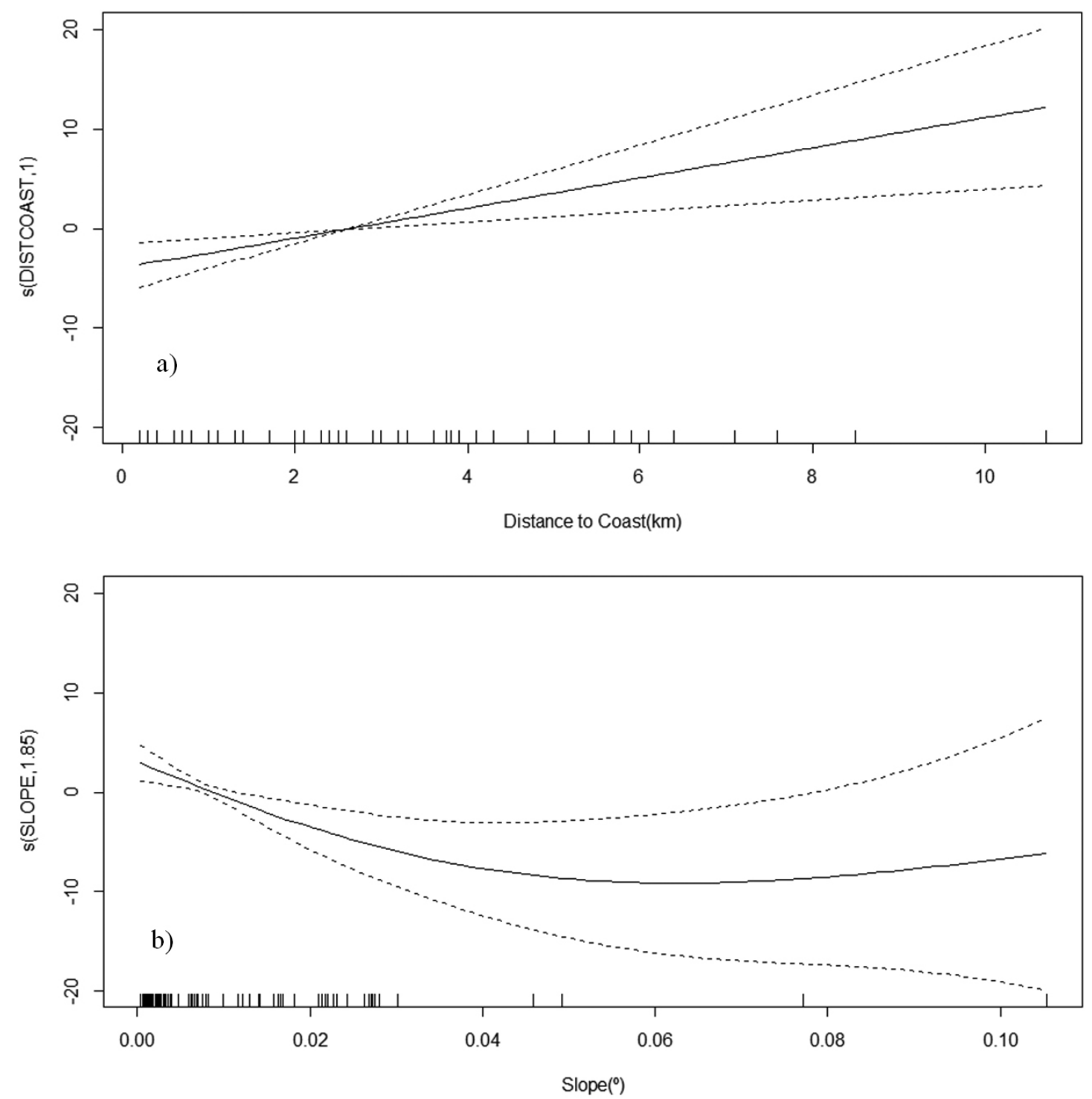

Figure 5. Generalized additive model smoothing curves for presence-absence model showing only significant parameters on Tursiops truncatus in Cabo Frio, RJ, Brazil. Y axis represents spline smooth functions and degrees of freedom are shown in parenthesis. Tickmarks in X axis indicate distribution of observations (with and without sightings). Dashed lines designate $95 \%$ confidence interval for smoothing functions. a) Distance to coast, b) Slope.

and connection with open ocean is, thus, closer. Therefore, the distribution pattern inside Cabo Frio region may be driven not only by feeding purposes but as a defense strategy against open ocean predators.

However, the fast human development in Cabo Frio may threaten this important area in terms of food resources and shelter against predators. The increasing fishing and touristic activities, especially during summer, are intense and may alter dolphins' behavior as seen in other places (e.g. such as in New Zealand - Lusseau 2003). Despite dolphin watching tourism seems not to be constant at the region, a high number of touristic and fishery boats, may be affecting their behavior. Thus, these activities may restrict dolphins' patterns of distribution in Cabo Frio, in which they could be avoiding areas with high concentration of boats and therefore constraining their home range. More data are needed to test this hypothesis, but these considerations may help to investigate if there are seasonal shifts of distribution driven by anthropogenic factors in Cabo Frio.

The formulation, development and validation of distribution models to the species at the area will allow a deeper understanding of how T. truncatus uses the region. This knowledge may allow that effective conservation actions may be used, especially in this highly touristic area. Furthermore, to understand the processes that drive the distribution of the species in this area is a beginning to understand general patterns that may influence T. truncatus distribution in Southwestern Atlantic Ocean. 


\section{Acknowledgments}

We thank Paulo De Marco Jr for comments on the manuscript.

We thank Sergio S. Moreira, Elaine Fidalgo and Lélis Antonio Carlos Junior for ARCGIS support. Luciana D. Figueiredo, Israel S. Maciel, Liliane Lodi, Marco Aurelio Crespo and Elaine C. S. Oliveira for their valuable support in the field. The authors gratefully acknowledge research grants from Conselho Nacional de Desenvolvimento Científico e Tecnológico - CNPq (Grant \# 479348/2010-3). We also thank the Fundação de Amparo à Pesquisa do Estado do Rio de Janeiro (FAPERJ) for scholarship to R.H.O. Tardin, (Process \# E-26/100.866/2011) and Conselho Nacional de Pesquisa e Desenvolvimento for Productivity Grant to M.A.S. Alves (Process \# 308792/2009-2).

\section{References}

Acevedo-Gutierrez A, 2008. Habitat Use. In: Perrin WF, Würsig B \& Thewissen JGM (Eds.). Encyclopedia of Marine Mammals. Academic Press. p. 524-529.

Anderwald $\mathrm{P}$ et al., 2012. Spatial scale and environmental determinants in minke whale habitat use and foraging. Marine Ecology Progress Series, 450:259-274. http://dx.doi. org/10.3354/meps09573

Azzelino et al., 2012. Predictive habitat models for managing marine areas: Spatial and temporal distribution of marine mammals within the Pelagos Sanctuary (Northwestern Mediterranean sea). Ocean \& Coastal Management, 67:63-74. http://dx.doi.org/10.1016/j.ocecoaman.2012.05.024

Baracho C et al., 2008. The occurrence of bottlenose dolphins (Tursiops truncatus) in the biological reserve of Atol das Rocas in north-eastern Brazil. Journal of Marine Biological Association of the United Kingdom 2 - Biodiversity Records, 1:1-4.

Barreto AS, 2011. Golfinho nariz de garrafa. In: Rocha-Câmara CC, Câmara IG \& Pretto DJ. Plano Nacional de Ação de Pequenos Cetáceos. Instituto Chico Mendes de Conservação da Biodiversidade. p. 27-29.

Bailey H \& Thompson PM, 2009. Using marine mammal habitat modelling to identify priority conservation zones within a marine protected area. Marine Ecology Progress Series, 378:279-287. http://dx.doi.org/10.3354/meps07887

Blasi MF \& Boitani F, 2012. Modelling fine-scale distribution of the bottlenose dolphin Tursiops truncatus using physiographic features on Filicudi (southern Thyrrenian Sea, Italy). Endangered Species Research, 17:269-288. http:// dx.doi.org/10.3354/esr00422

Bräger S, Harraway JA \& Manly BFJ, 2003. Habitat selection in a coastal dolphin species (Cephalorhynchus hectori). Marine Biology, 143:233-244. http://dx.doi.org/10.1007/ s00227-003-1068-x

Burnham KP \& Anderson DR, 2002. Multimodel Inference Understanding AIC and BIC in Model Selection. Sociological Methods and Research, 33:261-304. http:// dx.doi.org/10.1177/0049124104268644
Caon G \& Ott PH, 2004. Populações oceânicas de golfinhonariz-de-garrafa (Tursiops truncatus): fotoidentificação e fidelidade no Arquipélago de São Pedro e São Paulo, nordeste do Brasil. In: Resúmenes $11^{a}$ Reunión de Trabajo de Especialistas en Mamíferos Acuáticos de America del Sur, Resúmenes $5^{\circ}$ Congreso de La Sociedad Latinoamericana de Especialistas en Mamíferos Acuáticos; 2004; Quito. Quito. p. 44.

Cañadas A, Sagarminaga R, García-Tiscar S, 2002. Cetacean distribution related with depth and slope in the Mediterranean waters off southern Spain. Deep-Sea Research Part I: Oceanographic Research Papers, 49:2053-2073. http:// dx.doi.org/10.1016/S0967-0637(02)00123-1

Cañadas A et al., 2005. Habitat preference modelling as a conservation tool: proposals for marine protected areas for cetaceans in southern Spanish waters. Aquatic Conservation: Marine and Freshwater Ecosystems, 15:495-521. http:// dx.doi.org/10.1002/aqc.689

Carbonel C, 1998. Modelling of upwelling in the coastal area of Cabo Frio (Rio de Janeiro - Brazil). Revista Brasileira de Oceanografia, 46:1-17. http://dx.doi.org/10.1590/ S1413-77391998000100001

Carvalho MS \& Rossi-Santos MR, 2011. Sightings of the bottlenose dolphin (Tursiops truncatus) in Trindade island, South Atlantic Ocean. Marine Biodiversity Records, 4:1-4. http://dx.doi.org/10.1017/S1755267211000029

Connor RC, Read AJ \& Wrangham R, 2000. Male reproductive strategies and social bonds. In: Mann J et al. (Eds.). Cetacean societies: Field studies of dolphins and whales. Chicago: The University of Chicago Press. p. 247-269.

Corkeron PJ et al., 2011. Spatial models of sparse data to inform cetacean conservation planning: an example from Oman. Endangered Species Research, 15:39-52. http://dx.doi. org/10.3354/esr00367

Costa D, 2008. Energetics. In: Perrin WF, Würsig B \& Thewissen JGM (Eds.). Encyclopedia of Marine Mammals. Academic Press. p. 383-390. PMid:18491061.

Dalla Rosa L, Ford JK \& Trites AW, 2012. Distribution and relative abundance of humpback whales in relation to environmental variables in coastal British Columbia and adjacent waters. Continental Shelf Research, 36:89-104. http://dx.doi.org/10.1016/j.csr.2012.01.017

De Leo FC \& Pires-Vanin AMS, 2006. Benthic megafauna communities under influence of the SACW (South Atlantic Central Water) intrusion onto the Brazilian Southeastern shelf: a comparison between an upwelling and a non-upwelling ecosystem. Journal of Marine Systems, 60:268284. http://dx.doi.org/10.1016/j.jmarsys.2006.02.002

Di Beneditto APM et al., 2001. Stomach contents of delphinids from Rio de Janeiro, southeastern Brazil. Aquatic Mammals, 27:24-28.

Ferreira CEL et al., 2004. Trophic structure patterns of Brazilian reef fishes: a latitudinal comparison. Journal of Biogeography, 31:1093-1116. http://dx.doi. org/10.1111/j.1365-2699.2004.01044.x

Forney K, 2001. Environmental models of cetacean abundance: reducing uncertainty in population trends. Conservation Biology, 14:1271-1286. http://dx.doi. org/10.1046/j.1523-1739.2000.99412.x 
Garaffo GV et al., 2007. Habitat use by dusky dolphin in Patagonia: how predictable is their location? Marine Biology, 152:165-177. http://dx.doi.org/10.1007/ s00227-007-0686-0

Garaffo GV et al., 2010. Dusky dolphin: modeling habitat selection. Journal of Mammalogy, 91:54-65. http://dx.doi. org/10.1644/09-MAMM-A-105R1.1.

Garaffo GV et al., 2011. Modeling habitat use for dusky dolphin and Commerson's dolphin in Patagonia. Marine Ecology Progress Series, 421:217-227. http://dx.doi.org/10.3354/ meps08912

Gilles A et al., 2011. Modelling harbour porpoise seasonal density as a function of the German Bight environment: implications for management. Endangered Species Research, 14:157-169. http://dx.doi.org/10.3354/esr00344

Guisan A, Edwards TC Jr \& Hastie T, 2002. Generalized linear and generalized additive models in studies of species distributions: setting the scene. Ecological Modelling 157:89100. http://dx.doi.org/10.1016/S0304-3800(02)00204-1

Hastie TJ \& Tibshirani RJ, 1990. Generalized Additive Models. Chapman \& Hall.

Instituto Brasileiro do Meio Ambiente e dos Recursos Naturais Renováveis - IBAMA, 2001. Mamíferos Aquáticos do Brasil: Plano de Ação. versão II. Brasília: Diretoria de Fauna e Recursos Pesqueiros, IBAMA. 96 p.

Keiper CA et al., 2005. Marine mammal occurrence and ocean climate off central California, 1986 to 1994 and 1997 to 1999. Marine Ecology Progress Series, 289:285-306. http://dx.doi. org/10.3354/meps 289285

Keller CA et al., 2012. Application of a habitat model to define calving habitat of the North Atlantic right whale in the southeastern United States. Endangered Species Research, 18:73-87. http://dx.doi.org/10.3354/esr00413

Kim YJ \& Gu C, 2004. Smoothing spline Gaussian regression: more scalable computation via efficient approximation. Journal of the Royal Statistical Society Series B, 66:337-356. http://dx.doi.org/10.1046/j.1369-7412.2003.05316.x

Lodi L \& Monteiro-Neto C, 2012. Group size and composition of Tursiops truncatus (Cetacea: Delphinidae) in a coastal insular habitat off southeastern Brazil. Biotemas, 25:157-164. http://dx.doi.org/10.5007/2175-7925.2012v25n2p157

Lodi L et al., 2008. Movements of the Bottlenose Dolphin (Tursiops truncatus) in the Rio de Janeiro state, southeastern Brazil. Biota Neotropica, 8:205-209. http://dx.doi.org/10.1590/ S1676-06032008000400020

Lusseau D, 2003. Effects of tour boats on the behavior of the bottlenose dolphins: using Markov Chains to model anthropogenic impacts. Conservation Biology, 17:1785-1793. http://dx.doi.org/10.1111/j.1523-1739.2003.00054.x

Marubini F et al., 2009. Habitat preferences and interannual variability in occurrence of the harbour porpoise Phocoena phocoena off northwest Scotland. Marine Ecology Progress Series, 381:397-310. http://dx.doi.org/10.3354/meps07893
Nery MF, Espécie MA \& Simão SM, 2008. Marine tucuxi dolphin (Sotalia guianensis) injuries as a possible indicator of fisheries interaction in southeastern Brazil. Journal of Oceanography, 56:313-316.

R Core Team, 2012. R: A language and environment for statistical computing. Vienna: R Foundation for Statistical Computing. Available from: <http://www.R-project.org/>.

Redfern JV et al., 2006. Techniques for cetacean-habitat modeling. Marine Ecology Progress Series, 310:271-295. http://dx.doi.org/10.3354/meps310271

Silva JM Jr \& Silva FJL, 2004. Interação agonística de Stenella longirostris com Stenella attenuata e Tursiops truncatus no arquipélago de Fernando de Noronha, Brasil. In: Resúmens $11^{a}$ Reunión de Trabajo de Especialistas en Mamíferos Acuáticos de America del Sur, Resúmens $5^{\circ}$ Congreso de la Sociedad Latinoamericana de Especialistas en Mamíferos Acuáticos; 2004; Quito. Quito. p. 32.

Silva MA et al., 2008. Ranging patterns of bottlenose dolphins living in oceanic waters: implications for population structure. Marine Biology, 156:179-192. http://dx.doi.org/10.1007/ s00227-008-1075-Z

Smolker RA et al., 1992. Sex differences in patterns of association among Indian Ocean bottlenose dolphins. Behaviour, 123:38 69. http://dx.doi.org/10.1163/156853992X00101

Van Bressem MF, Santos MCO \& Oshima JE, 2009. Skin diseases in Guiana dolphins (Sotalia guianensis) from the Paranaguá estuary, Brazil: a possible indicator of a compromised marine environment. Marine Environmental Research, 67:63-68. http://dx.doi.org/10.1016/j.marenvres.2008.11.002

Viddi FA et al., 2010. Spatial and seasonal variability in cetacean distribution in the fjords of northern Patagonia, Chile. ICES Journal of Marine Science, 67:959-970. http://dx.doi. org/10.1093/icesjms/fsp288

Wells RS, 1991. The role of long-term study in understanding the social structure of a bottlenose community. In: Pryor K \& Norris KS (Eds.). Dolphin societies: discoveries and puzzles. Los Angeles: University of California Press. p. 199-225.

Wells RS \& Scott M, 2008. Common bottlenose dolphin. In: Perrin WF, Würsig B \& Thewissen JGM (eds.). Encyclopedia of Marine Mammals. Academic Press. p. 255-259.

Wood SN, 2006. Generalized Additive Models: an introduction with R. Chapman \& Hall. 410 p.

Wood SN, 2011. Fast stable restricted maximum likelihood and marginal likelihood estimation of semiparametric generalized linear models. Journal of the Royal Statistical Society (B), 73:336. http://dx.doi.org/10.1111/j.1467-9868.2010.00749.x

Yee TW \& Mitchell ND, 1991. Generalized additive models in plant ecology. Journal of Vegetation Science, 2:587-602. http://dx.doi.org/10.2307/3236170

Received: January 2013

First Decision: February 2013 Accepted: May 2013 